\title{
Square Milligram per Square Deciliter
}

National Cancer Institute

\section{Source}

National Cancer Institute. Square Milligram per Square Deciliter. NCI Thesaurus. Code C122212.

A unit of mass concentration defined as one square milligram of a substance in unit volume of the mixture equal to one square deciliter. 